\title{
The Implementation of API RP 1102 Code to Evaluate Gas Pipeline Road Crossing
}

\author{
Nurhadi Siswantoro ${ }^{1, a, *}$, Muhammad Badrus Zaman ${ }^{1, b}$, Semin $^{1, c}$, and Dwi Priyanta ${ }^{1, d}$ \\ ${ }^{1}$ Department of Marine Engineering, Institut Teknologi Sepuluh Nopember, Surabaya, Indonesia \\ a.nurhadisukses@gmail.com,b.drus_zaman@yahoo.com,c.seminits@gmail.com, \\ d.priyanta@gmail.com \\ *corresponding author
}

Keywords: $\quad$ API RP 1102; Gas Pipeline; Road Crossing; and Stress Analysis

Abstract: This paper discussed about evaluation stress on gas pipeline. A pipeline transports LPG (Liquefied Petroleum Gas) from jetty to storage tank area along 1200 meters. The pipeline has nominal pipe size (NPS) 10 inches and buried in areas with high population levels (areas with high consequences). At KP 800 meter the segment of pipeline has road crossing conditions, where vehicles such as heavy vehicles pass across above. Pipeline has operated during about 8 years, it necessary study to evaluate the integrity or strength. One of the methods to evaluate buried and road crossing pipelines is determining stress occurs. Stress analysis for pipeline road crossing is evaluated using code API RP 1102 (Pipelines Crossing Railroads and Highway). Based on these standards, the pipeline road crossing is evaluated by stress components such as (a) Circumferential Stress, (b) Longitudinal Stress, (c) Radial Stress. The calculation will be analysed using spreadsheet modelling. Based on the stress analysis in existing operational condition, the segment in KP 800 is Acceptable according Standard API 1102. All parameters show acceptable, furthermore the pipeline is concluded in satisfactory condition.

\section{Introduction}

Terminal LPG company involved in the services of receiving, stockpiling and distributing the LPG. The company has responsible for ensuring its assets in high integrity. The process of receiving, stockpiling and distributing the LPG. The company has responsible for ensuring its assets in high integrity. The process of receiving, stockpiling and distribution starts from the Jetty head, which functions to carry out receipts from Tanker. In the jetty head there is a marine loading arm equipment that serves to connect the manifold pipe of the tanker with a pipe from the ground and transport LPG into a storage tank. The LPG pumping from the tanker uses a 10-inch diameter pipe along 1200 meters before entering the tank. The pipe is able to flow LPG from tankers up to 300 MT / hour.

Pipe is the main asset in transporting LPG from the process of reception (jetty head) to storage tank. At KP $00+800$ meters from the jetty head, pipes crossing the road. The greatest load due to 
the crossing when the heavy vehicle passes over. The heavy equipment that passes over the pipe is Komatsu PC-200 type with loads greater than 20 tons.

To ensure the integrity of the LPG pipeline that has been operating for 8 years, it is necessary to evaluate the strength of the pipeline. Pipe stress analysis is the most important method for convincing and numerically determining that piping systems in engineering are safe, or a method of stress calculation on pipes caused by static loads and dynamic loads that are the resultant effects of gravity, temperature change, pressure inside and outside the pipe, changes in the amount of fluid discharge flowing in the pipe and the effect of seismic forces [1].

API RP 1102 Steel Pipeline Crossing Railroad and Highways is one of the methods / standards to evaluate the strength of pipes that have undergone road crossing. In this standard, pipe will be evaluated based on longitudinal stress, circumference stress / Hoop stress, and radial stress [2].

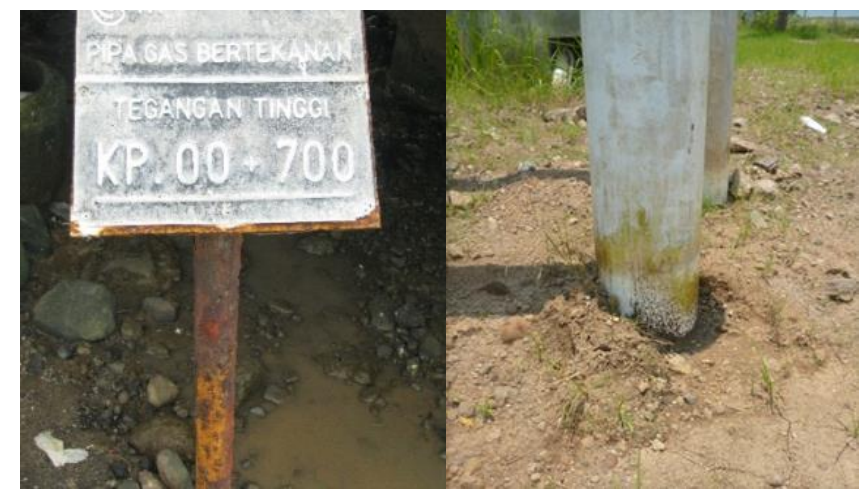

Figure 1: (a) Burried pipeline and before road crossing ; (b) Pipeline arrise after buried

\section{Methodology}

In evaluating the strength of the pipe, inspection is required to obtain the data for consideration in the calculation. Here are some documentation:

- Complete design and fabricarion drawing / as buid drawing.

- Manufacture data.

- Inspection Report.

- History records.

- A sketch showing the location of the thickness measurement.

- All records and repair performed along with procedures and test records.

Can be seen in Figure. 2, it shows flowchart methodology API calculation RP 1102. Based on the API 1102 standard, the road crossing pipeline is evaluated with concern to longitudinal stress, circumference stress / Hoop stress, and radial stress. Here are the stress components calculated on the road crossing pipeline:

a. Circumferential Stress

Circumferential Stress is affected by the following components:

- Circumferential stress due to earth load

$$
S_{H e}=K_{H e} B_{e} E_{e} \gamma D
$$

Where,

$S_{H e}=$ Circumferential stress due to earth load

$K_{H e}=$ Stiffness factor for circumferential stress from earth load 
$B_{e}=$ Burial factor for earth load circumferential stress

$E_{e}=\quad$ Excavation factor for earth load

$\gamma=$ Soil unit weight

$D \quad=\quad$ Pipe outside diameter

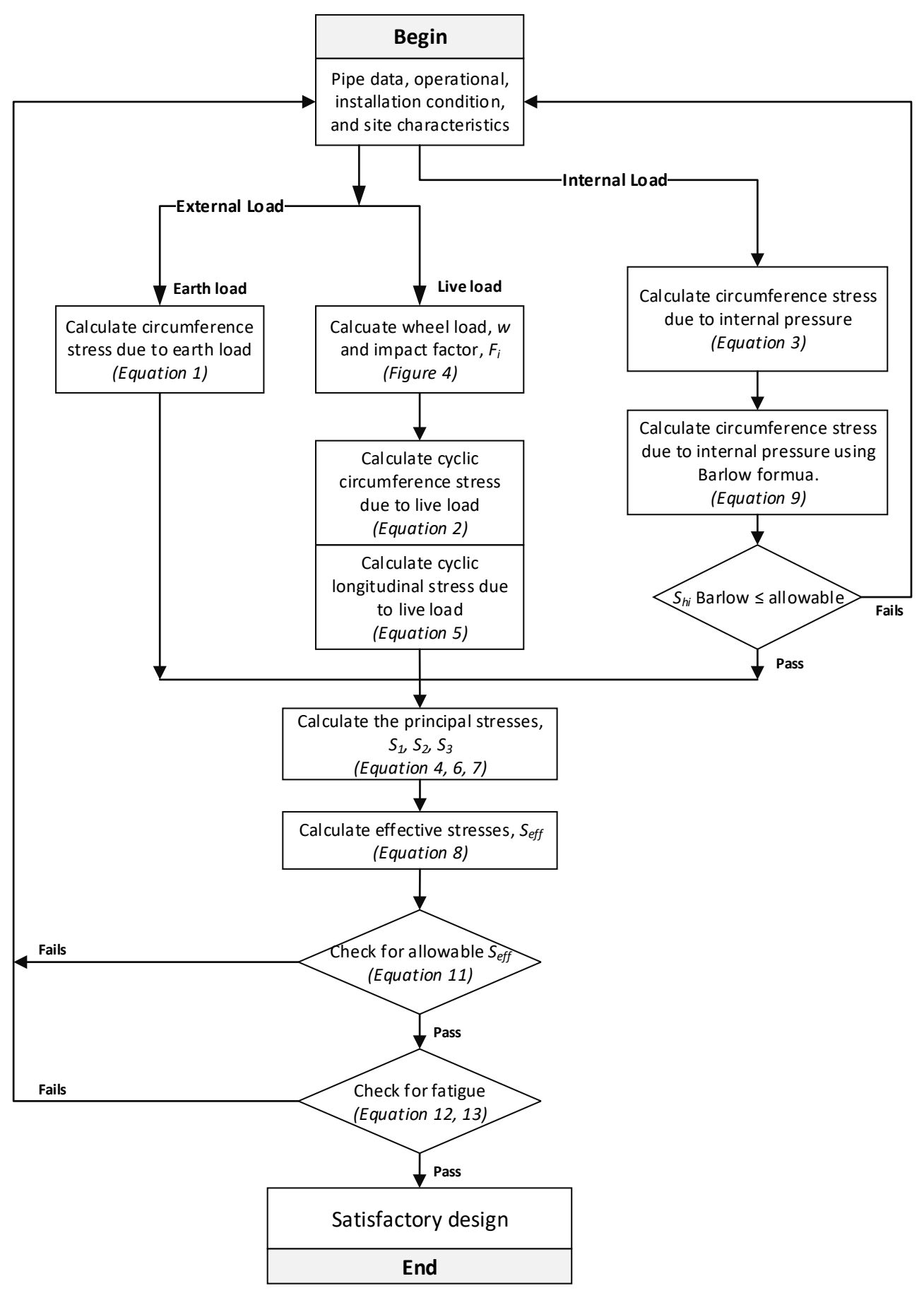

Figure. 2: Flowchart stress analysis pipeline road crossing based on API RP 1102 
- Circumferential stress due to internal pressure

$$
S_{H i}=\frac{p\left(D-t_{w}\right)}{2_{t w}}
$$

Where,

$S_{H i}=$ Circumferential stress due to internal pressure

$p=$ Maximum operating pressure

$D \quad=\quad$ Pipe outside diameter

$t_{w}=$ Wall thickness

- Maximum circumferential stress

$$
S_{1}=S_{H e}+\Delta S_{H}+S_{H i}
$$

b. Longitudinal Stress

Longitudinal Stress is affected by the following components:

- Longitudinal stress due to highway vehicular load

$$
\Delta S_{L k}=K_{L k} G_{L k} R L F_{i} w
$$

Where,

$\Delta \mathrm{S}_{\mathrm{Lk}}=$ Longitudinal stress due to highway vehicular load

$\mathrm{K}_{\mathrm{Lk}}=$ Highway stiffness factor for cyclic longitudinal stress

$\mathrm{G}_{\mathrm{Lk}}=$ Highway geometry factor for cyclic longitudinal stress

$\mathrm{R}=$ Highway pavement type factor

$\mathrm{L}=$ Highway axle configuration factor

$\mathrm{F}_{\mathrm{i}} \quad=$ Impact factor

$\mathrm{w}=$ Applied design surface pressure

$$
S_{2}=\Delta S_{L}-E_{S} \alpha_{T}\left(T_{2}-T_{1}\right)+V_{S}\left(S_{H e}+S_{H i}\right)
$$

where,

$\Delta S_{L} \quad=\quad$ Longitudinal stress due to highway vehicular load

$E_{S} \quad=\quad$ Young's modulus of steel

$\alpha_{T}=$ Coefficient of thermal expansion of steel

$T_{2}=$ Maximum or minimum operating temperature

$T_{1}=$ Temperature at time of installation

$V_{s} \quad=$ Poisson ratio of steel

$S_{H e}=$ Circumferential stress due to earth load

$S_{H i}=$ Circumferential stress due to internal pressure

c. Radial Stress

Radial Stress is affected by internal pressure.

$$
S_{\exists}=-P
$$


Where,

$S_{\exists} \quad=\quad$ Radial stress

$P \quad=\quad$ MOP (Maximum Operating Pressure)

\section{Result and Discussion}

\subsection{Pipe Data}

The basic technical data of pipes from jetty head to storage tank are as follows:
a. Service
: LPG
b. Material/Schedule
: API 5L Gr.B/Sch 40
c. SMYS
: $35000 \mathrm{psi}$
d. Nominal Diameter
: 10 inches
e. Outside Diameter
: 10.75 inches
f. Inside Diameter
: 10.02 inches
g. Thickness Nominal
0.365 inches
h. Type Joint
: ERW
i. Operating Pressure
: $130 \mathrm{psi}$
j. Operating Temperature $: 24.8-77 \mathrm{oF}$
k. Valve rating
: 300\#
1. flange rating
: 300\#
m. Design Factor
: 0.5 (Class Location 3)

\subsection{Stress Calculation}

1. Area condition of pipeline road crossing

The soil condition in the road crossing area is soft to medium clay category, and loose sand and gravel. The pipeline is located in an area with a density of $>46$ buildings and industrial, and as according to ASME B31.8 belongs to Class Location category 3 [3,5,6]. Maximum vehicle load received by pipe is Komatsu PC-200 with load more than 20 tons. Pipe buried with a depth of 2.7 meters. The specifications of Komatsu PC-200 can be seen in Figure. 3.

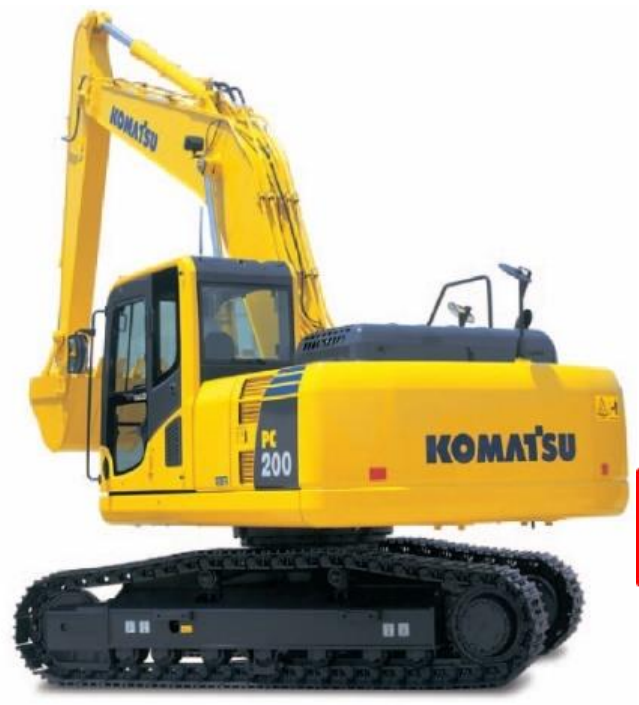

\begin{tabular}{|c|c|c|c|c|}
\hline \multirow[b]{2}{*}{ Shoes } & \multicolumn{2}{|c|}{ PC200-8 } & \multicolumn{2}{|c|}{ PC200LC-8 } \\
\hline & $\begin{array}{c}\text { Operating } \\
\text { Weight }\end{array}$ & \begin{tabular}{|c|} 
Ground \\
Pressure \\
\end{tabular} & $\begin{array}{c}\text { Operating } \\
\text { Weight }\end{array}$ & \begin{tabular}{|c|} 
Ground \\
Pressure \\
\end{tabular} \\
\hline $\begin{array}{c}500 \mathrm{~mm} \\
20^{\circ}\end{array}$ & $\begin{array}{l}19400 \mathrm{~kg} \\
42,770 \mathrm{lb}\end{array}$ & $\begin{array}{c}53.0 \mathrm{kPa} \\
0.54 \mathrm{kgf} / \mathrm{cm}^{2} \\
7.68 \mathrm{psi}\end{array}$ & - & - \\
\hline $\begin{array}{c}600 \mathrm{~mm} \\
24^{*}\end{array}$ & $\begin{array}{l}19500 \mathrm{~kg} \\
42,990 \mathrm{lb}\end{array}$ & $\begin{array}{c}45.1 \mathrm{kPa} \\
0.46 \mathrm{kgf} / \mathrm{cm}^{2} \\
6.54 \mathrm{psi}\end{array}$ & $\begin{array}{l}20630 \mathrm{~kg} \\
45,480 \mathrm{lb}\end{array}$ & $\begin{array}{c}43.1 \mathrm{kPa} \\
0.44 \mathrm{kgf} / \mathrm{cm}^{2} \\
6.26 \mathrm{psi}\end{array}$ \\
\hline $\begin{array}{c}700 \mathrm{~mm} \\
28^{\circ}\end{array}$ & $\begin{array}{l}19750 \mathrm{~kg} \\
43,540 \mathrm{lb}\end{array}$ & $\begin{array}{c}39.2 \mathrm{kPa} \\
0.40 \mathrm{~kg} / / \mathrm{cm}^{2} \\
5.69 \mathrm{psi}\end{array}$ & $\begin{array}{l}20900 \mathrm{~kg} \\
46,080 \mathrm{lb}\end{array}$ & $\begin{array}{c}37.3 \mathrm{kPa} \\
0.38 \mathrm{kgf} / \mathrm{cm}^{2} \\
5.40 \mathrm{psi}\end{array}$ \\
\hline $\begin{array}{c}800 \mathrm{~mm} \\
31.5^{\circ}\end{array}$ & $\begin{array}{l}20010 \mathrm{~kg} \\
44,110 \mathrm{lb}\end{array}$ & $\begin{array}{c}34.3 \mathrm{kPa} \\
0.35 \mathrm{kgf} / \mathrm{cm}^{2} \\
4.98 \mathrm{psi}\end{array}$ & $\begin{array}{l}21180 \mathrm{~kg} \\
46,690 \mathrm{lb}\end{array}$ & $\begin{array}{c}33.3 \mathrm{kPa} \\
0.34 \mathrm{kgf} / \mathrm{cm}^{2} \\
4.83 \mathrm{psi}\end{array}$ \\
\hline $\begin{array}{c}900 \mathrm{~mm} \\
35.5^{\circ}\end{array}$ & - & - & $\begin{array}{l}21460 \mathrm{~kg} \\
47,310 \mathrm{lb}\end{array}$ & $\begin{array}{c}29.4 \mathrm{kPa} \\
0.30 \mathrm{kgf} / \mathrm{cm}^{2} \\
4.27 \mathrm{psi}\end{array}$ \\
\hline
\end{tabular}

Figure 3: (a) (b) The specification of Komatsu PC-200 
2. Wheel load

Wheel loads by ground-contact Komatsu PC-200 at a depth of 2.7 meters shall be correlated with Impact Factor values. Impact Factor for highways $1-1.5$ and decreased 0.03 per $\mathrm{ft}(0.1 \mathrm{per} \mathrm{m})$ to depths below $5 \mathrm{ft}(1.5 \mathrm{~m})$. Because of the burried pipe depth of $2.7 \mathrm{~m}$, the impact factor \pm 1.4 . The impact factor graph can be seen in Figure 4.

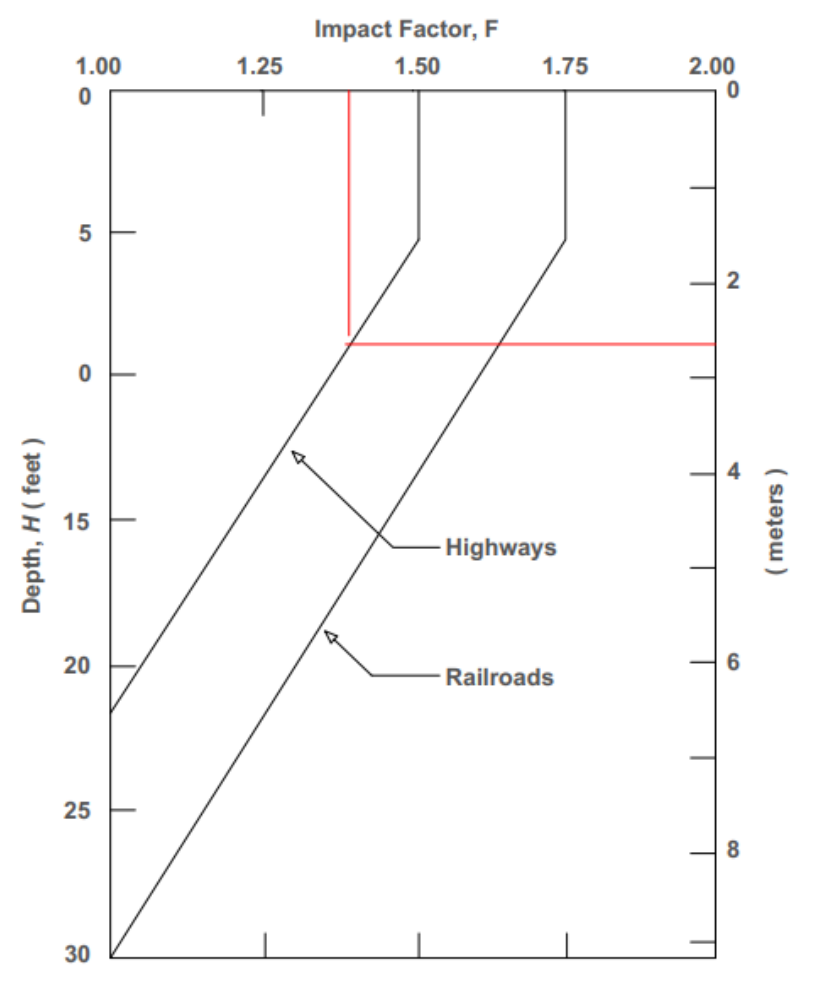

Figure 4: Recommended impact factor versus depth

For Komatsu PC-Bego 200 used the value of impact factor of 1.4, it becomes the size of wheel loads is $6.97 \mathrm{lb} / \mathrm{in} 2$.

3. Circumference stress

Circumference stress is caused by earth load, vehicular load, and internal pressure. The circumference stress calculation uses (1), (2), and (3).

- Earth Load

Table 1 is the summary calculation on circumference due to earth load ( $\mathrm{SHe}$ ) based on (1).

Table 1: Summary Calculation Circumference due to Earth Load

\begin{tabular}{|l|l|c|l|c|c|}
\hline $\boldsymbol{K}_{\boldsymbol{H} \boldsymbol{\theta}}$ & $\boldsymbol{B}_{\boldsymbol{\theta}}$ & $\boldsymbol{E}_{\boldsymbol{\theta}}$ & $\begin{array}{c}\boldsymbol{\gamma} \\
\text { (lb/in }^{\mathbf{3}} \text { ) }\end{array}$ & $\begin{array}{c}\boldsymbol{D} \\
\text { (inch) }\end{array}$ & $\begin{array}{c}\boldsymbol{S}_{\boldsymbol{H} \boldsymbol{\theta}} \\
(\mathbf{p s i})\end{array}$ \\
\hline 800 & 1.3 & 1 & 0.069 & 10.75 & 771.42 \\
\hline
\end{tabular}

- Vehicular Load

Table 2 is a summary of calculations on circumference due to vehicular load ( $\mathrm{SHh}$ ) based on (2). 
Table 2: Summary Calculation Circumference due to Vehicular Load

\begin{tabular}{|c|c|c|c|c|c|c|}
\hline $\boldsymbol{K}_{\boldsymbol{H} \boldsymbol{k}}$ & $\boldsymbol{G}_{\boldsymbol{H} \boldsymbol{k}}$ & $\boldsymbol{R}$ & $\boldsymbol{L}$ & $\boldsymbol{F}_{\boldsymbol{i}}$ & $\begin{array}{c}\boldsymbol{W} \\
\left(\mathbf{l b} / \mathbf{i n}^{2}\right)\end{array}$ & $\begin{array}{c}\Delta \boldsymbol{S}_{\boldsymbol{H} \boldsymbol{k}} \\
(\mathbf{p s i})\end{array}$ \\
\hline 11 & 0.85 & 1.1 & 1 & 1.4 & 6.97 & 100.39 \\
\hline
\end{tabular}

- Internal Pressure

Table 3 is summary calculation on circumference due to internal pressure $\left(\mathrm{S}_{\mathrm{Hi}}\right)$ based on (3).

Table 3: Summary Calculation Circumference due to Internal Pressure

\begin{tabular}{|c|c|c|c|}
\hline $\begin{array}{c}p \\
(\mathbf{p s i})\end{array}$ & $\begin{array}{c}\boldsymbol{D} \\
\text { (inch) }\end{array}$ & $\begin{array}{c}\boldsymbol{t}_{\boldsymbol{w}} \\
\text { (inch) }\end{array}$ & $\begin{array}{c}\boldsymbol{S}_{\boldsymbol{H} \text { i }} \\
(\mathbf{p s i})\end{array}$ \\
\hline 130 & 10.75 & 0.365 & 1849.38 \\
\hline
\end{tabular}

Total of circumference stress is sum of earth load, vehicular load and internal pressure. From the calculation, total of circumference stress is 2721.19 psi.

4. Longitudinal stress

Longitudinal stress, caused by vehicular load. The calculation of longitudinal stress using (5). After calculating the longitudinal load due to vehicular load, then maximum longitudinal stress may be used in the (6). Table 4 is summary calculation on longitudinal stress.

Table 4: Summary of Calculation of Maximum Longitudinal Stress

\begin{tabular}{|l|l|l|l|l|c|c|}
\hline $\boldsymbol{K}_{\boldsymbol{L k}}$ & $\boldsymbol{G}_{\boldsymbol{L k}}$ & $\boldsymbol{R}$ & $\boldsymbol{L}$ & $\boldsymbol{F}_{\boldsymbol{i}}$ & $\begin{array}{c}W \\
\left(\mathbf{l b}_{\mathbf{i n}} \mathbf{2}^{\mathbf{2}}\right)\end{array}$ & $\begin{array}{c}\Delta \boldsymbol{S}_{\boldsymbol{L} k} \\
(\mathbf{p s i})\end{array}$ \\
\hline 10.5 & 1 & 1.1 & 1 & 1.4 & 6.97 & 112.74 \\
\hline
\end{tabular}

The maximum of longitudinal stress from calculation based on (6) is $2339 \mathrm{psi}$

5. Radial stress

Radial stress, caused by internal pressure. By the data of pipe, the maximum operating pressure (MOP) is 130 psi. So, the radial stress is equivalent with the MOP -130 psi.

6. Effective stress

After the total of maximum stress, the next step is continued to calculate total effective stress from (8).

$$
S_{\text {eff }}=\sqrt{\frac{1}{2}\left[\left(S_{1}-S_{2}\right)^{2}+\left(S_{2}-S_{3}\right)^{2}+\left(S_{3}-S_{1}\right)^{2}\right]}
$$

Where,

$\mathrm{S} 1$ = Maximum circumferential stress, psi

$\mathrm{S} 2$ = Maximum longitudinal stress, psi

S3 = Maximum radial stress, psi

From this formula, total effective stress (Seff) is $\mathbf{2 6 8 1}$ psi.

7. Check for calculation stress

From previous calculation, the next steps are checked for the maximum stress based on Barlow Formula and Effective Stress. 


\section{- $\quad$ First check for circumferential stress (Barlow formula)}

Checking for the safety at internal pressurization is accomplished by assuring that the circumferential stress due to internal pressure calculated by Barlow formula is less than the factored specified minimum yield strength [3,4]. Barlow stress formula is shown in (9).

$$
S_{H i}(\text { Barlow })=p D / 2 t_{w}
$$

The calculation of $S_{H i}$ (Barlow) is $\mathbf{1 9 1 4}$ psi. Stress level is acceptable if:

$$
\text { SHi (Barlow) } \leq F \times E \times T \times S M Y S
$$

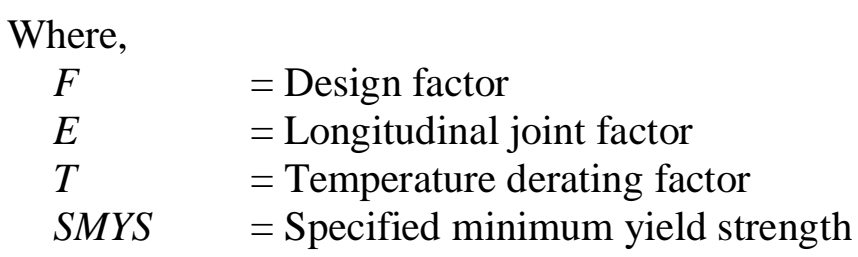

From this calculation of $F \times E x T \times S M Y S=17500$ psi. Since SHi (Barlow) less than 17500 psi, then $S_{H i}$ (Barlow) is Acceptable.

\section{- Second check for total effective stress}

The check against yielding of the pipeline is accomplished by assuring that the total effective stress is less than the factored specified minimum yield strength.

The calculation of total effective stress is $\mathbf{2 6 8 1}$ psi. Stress level is acceptable if:

$$
S_{\text {eff }} \leq F \times S M Y S
$$

From this calculation of $F x S M Y S=17500$ psi. Since $S_{\text {eff }}$ less than 17500 psi, then $S_{\text {eff }}$ is Acceptable.

8. Check for fatigue

The check for fatigue is accomplished by comparing a stress component normal to weld in the pipeline againts an allowable value of this stress, referred to as a fatigue endurance limit.

\section{- First check for potential fatigue in girth weld}

The cyclic stress that must be checked for potential fatigue in a girth weld located beneath a roadcrossing is the longitudinal stress due to live load. The design check is accomplished by asuring that the live load cyclic longitudinal stress is less than the factored fatigue endurance limit. The girth weld check is given by the following

$$
\triangle S L h \leq S F G \times F
$$

From this calculation of $S F G \times F=6000$ psi, and $\triangle S L h$ from Table 4 is 112.74 psi. Since $\Delta S L h$ less than 6000 psi, then potential fatigue in girth weld is Acceptable. 


\section{- Second check for potential fatigue in longitudinal weld}

The cyclic stress that must be checked for potential fatigue in a girth weld located beneath a roadcrossing is the circumferential stress due to live load. The design check is a accomplished by asuring that the live load cyclic circumferential stress is less than the factored fatigue endurance limit. The longitudinal weld check is given by the following

$$
\Delta S_{H h} \leq S_{F L} x F
$$

From this calculation of $S_{F L} x F=10500$ psi, and $\Delta S_{H h}$ from Table II is 100.39 psi. Since $\Delta S_{H h}$ less than 10500 psi, then potential fatigue in longitudinal weld is Acceptable.

\section{Conclusions}

The Pipeline transports LPG from jetty to storage tank area along 1200 meters. The pipeline has nominal pipe size (NPS) 10 inches and buried in areas with high population levels (areas with high consequences). At KP 800 meter the segment of pipeline has road crossing conditions. Based on the stress analysis in existing operational condition, the segment in KP $00+800$ is Acceptable according Standard API 1102. From the calculation and checking all parameters the segment in KP $00+800$ is Acceptable by checked for four parameters:

- Acceptable by checked circumference stress (Barlow Stress),

- Acceptable by checked total effective stress,

- Acceptable by checked potential fatigue in girth weld,

- Acceptable by checked potential fatigue in longitudinal weld.

All parameters show acceptable, so it can be concluded that the pipeline is in satisfactory condition.

\section{References}

[1] Liang-Chuan and Tsen-Loong, Pipe Stress Engineering. New York: USA, 2009.

[2] The American Petroleum Institute, API RP 1102, Steel Pipelines Crossing Railroads and Highways. Washington DC: USA, 2007.

[3] The American Society of Mechanical Engineer, ASME B31.8 Gas Transmission and Distribution Piping Systems. New York: USA, 2007.

[4] The American Petroleum Institute, API 570 Piping Inspection Code Second Edition : Inspection, Repair, Alteration, and Rerating of In-service Piping Systems. Washington DC: USA, 2012.

[5] The American Society of Mechanical Engineer, ASME B36.10M Welded and Seamless Wrought Steel Pipe. New York: USA, 2004.

[6] Alkazraji, Duraid, A Quick Guide to Pipeline Engineering. Abington Cambridge: UK, 2008. 